NASA Technical Memerandum 100105

\title{
Observations of Directional Gamma Prime Coarsening During Engine Operation
}

\author{
(NASA-TM-100105) OBSERVATIONS OF \\ DIRECTIONAL GAMMA PEIME COABSENING DURING \\ N 87-25459 \\ ENGINE OPERATION (NASA) $11 \mathrm{p}$ AVail: NTIS \\ HC $\quad 02 / M F \quad A 01$ \\ $\operatorname{CscL} 11 \mathrm{~F}$ \\ $\begin{array}{ll}\text { G } 3 / 26 & \text { Unclas } \\ 0083965\end{array}$
}

Susan L. Draper, David R. Hull, and Robert L. Dreshfield

Lewis Research Center

Cleveland, Ohio

Prepared for the

TMS Annual Meeting sponsored by the AIME

Denver, Colorado, February 23-26, 1987 
OBSERVATIONS OF DIRECTIONAL GAMMA PRIME COARSENING DURING ENGINE OPERATION

\author{
Susan L. Draper, David R. Hul1, and Robert L. Dreshfield \\ National Aeronautics and Space Administration \\ Lewis Research Center \\ Cleveland, Ohio 44135
}

\begin{abstract}
SUMMARY
Two alloys with negative mismatch parameters, NASAIR 100 and a modified NASAIR 100 called Alloy 3 were run as turbine blades in an experimental groundbased Garrett TFE731 engine for up to $200 \mathrm{hr}$. The directional coarsening of $\gamma^{\prime}$ (rafting) that developed during engine testing was analyzed and compared to previous research from laboratory tests. The blades were found to be rafted normal to the centrifugal stress axis over much of the span, but near the surfaces, the blades were found to be rafted parallel to the centrifugal stress axis for certain cycles. Representative photomicrographs of the blades and the effects of stress and temperature on raft formation are shown.
\end{abstract}

\title{
INTRODUCTION
}

Stress induced directional coarsening (rafting) of $\gamma^{\prime}$ in single crystal nickel-base superalloys has been extensively studied in numerous laboratories during the last decade. The studies have generally been concerned with either the beneficial effects of rafting on creep-rupture behavior or the kinetics of rafting in isothermal laboratory conditions.

Two alloys (NASAIR 100 and Alloy 3), developed by Garrett Turbine Engine Company under NASA Contract NAS3-20073 (MATE), have been observed to form $\gamma^{i}$ rafts in laboratory creep tests (refs. 1 and 2). Turbine blades made of these alloys were tested in a ground-based engine as part of the Garrett program and were found to have formed rafts during the engine operation (ref. 3).

The work reported here was initiated to examine in more detafl the rafting response of these alloys. In particular, to determine the range of stress and temperature over which rafting might occur in actual turbine engine operations and to make observations relating to raft formation during the conditions of turbine engine operation.

\section{BACKGROUND}

Solid turbine blades made from the two alloys were run in a series of ground-based engine tests performed by the Garrett Turbine Engine Company in a specially modified TFE731 turbofan engine (refs. 3 and 5 ). The engine test consisted of the four $50 \mathrm{hr}$ segments shown in figure 1. The first segment was to evaluate high cycle fatigue (fig. $1(\mathrm{a})$ ). The second segment evaluated maximum continuous temperature conditions (fig. $1(\mathrm{~b})$ ). The third segment evaluated low cycle fatigue (fig. 1(c)), while the last segment simulated an aircraft mission (fig. $1(d))$. After each segment, the turbine was disassembled and the blades were inspected. When the engine was reassembled, some blades were replaced according to a schedule that allowed having blades that received 
all test segments, or any combination of test segments. Blades examined in this study received efther all test cycles, cycles $B$ and $D$, or cycles $C$ and D. While the total engine test time was $200 \mathrm{hr}$, the time at or above maximum continuous power was significantiy less. Those blades exposed to all cycles had $78.5 \mathrm{hr}$ at maximum temperature conditions. Blades exposed to cycles $B$ and $D$ received $55.5 \mathrm{hr}$ and cycles $C$ and $D$ received only $27.5 \mathrm{hr}$ at maximum temperature conditions.

The average blade temperature and stress at the maximum continuous power setting is shown in figure 2. The maximum blade temperature, found near mid span, was approximately $1760^{\circ} \mathrm{F}$. The temperature varied from about $1605^{\circ} \mathrm{F}$ at the blade hub to $1570^{\circ} \mathrm{F}$ at the tip. It should be noted that the middle 50 percent ( 25 to 75 ) was nearly isothermal, varying by only about $20^{\circ} \mathrm{F}$.

The maximum stress of 25000 psi occurred at the blade hub. The stress decreased markedly, to about $20000 \mathrm{psi}$, between the blade hub and 15 percent of the span. Between 15 and 55 percent span the stress decreased only slightly from about 20000 to $18000 \mathrm{psi}$. Between 55 and 75 percent span, the stress decreased from about 18000 to 13000 psi while the temperature was virtually isothermal.

\section{MATERIAL AND EXPERIMENTAL METHODS}

The two alloys used in this investigation were developed by the Garrett Turbine Engine Company (refs. 4 and 5) in collaboration with Cannon-Muskegon. Both alloys are single crystal derivatives of Mar-M 247. The chemical analyses of NASAIR 100 and Alloy 3 are shown in table 1 . The major difference between the alloys is that Alloy 3 has 5 percent cobalt while NASAIR 100 has none. The cobalt addition to Alloy 3 combined with its slightly reduced refractory metal levels stabilize the alloy relative to a tungsten and $\mu$ phase precipitation.

The blades were sectioned at approximately one third and two thirds of the chord length (fig. 3(a)). The cross section at one third of the chord was defined as the leading edge and the cross section at two thirds of the chord was defined as the trailing edge. The cross sections were polished and etched with $33 \mathrm{ml}-\mathrm{HNO}_{3}, 33 \mathrm{ml}$-Acetic acid, $33 \mathrm{ml}-\mathrm{H}_{2} \mathrm{O}, 1 \mathrm{ml}-\mathrm{HF}$. SEM photomicrographs were taken at $1 \mathrm{~mm}$ intervals along the length of the blade to characterize the changing morphology of the $\gamma$ and $\gamma^{\prime}$ phases. The thickness of the $\gamma$ and $r^{\prime}$ phases, in the directions normal and parallel to the centrifugal stress axis, were measured using a line intercept technique on a Zeiss Videoplan 2 digitizing tablet.

\section{RESULTS}

Representative photomicrographs, shown in figures $3(b)$ to (d), 1llustrate the morphology of the $Y$ and $Y^{\prime}$ phases along the span of the blade after engine testing. The photomicrograph in figure $3(b)$ was taken at 6 percent of the span and is typical of the morphology near the blade hub. Figure $3(c)$, taken at 24 percent of the span, fllustrates the directional coarsening of the $\gamma^{\prime}$ perpendicular to the centrifugal stress axis. The morphology near the tip ( 82 percent span) is also cuboidal as shown in figure $3(d)$. 
The changing morphology of the phases along the span of a blade exposed to all four engine cycles is quantified in figure 4 . The profile shown in figure 4 was typical for a given blade. Both leading and trailing edges exhibited similar rafting behavior with only the amount of the span length rafted varying. The thickness of the $\gamma^{\prime}$ parallel to the stress axis, remains essentially constant over the span of the blade; however, slight $\gamma^{\prime}$ particle coarsening was observed at the blade hub due to the higher operating temperatures at this location. The $r$ phase, parallel to the stress axis, thickened upon rafting to approximately three times its original thickness.

The rafting behavior for NASAIR 100 given all four cycles is illustrated in figure 5 by plotting the aspect ratio (thickness normal to stress direction to thickness parallel to stress direction) versus the span of the blade, with the average stress and temperature profile overlaid for comparison. A microstructure was arbitrarily defined to be fully rafted if its aspect ratio was $\mathbf{2 . 5}$ or greater. Also note that the aspect ratios for $Y$ and $\gamma^{\prime}$ were nearly identical.

The range of the span rafted depended on the alloy and the engine cycle the blade was exposed to, as shown in figure 6 . NASAIR 100 rafted over 60 percent of the span length while Alloy 3 rafted over only 39 percent of the span length when exposed to the same engine cycles. The percent of span length rafted increased with time at maximum temperature. A NASAIR 100 blade, exposed to engine cycles $C$ and $D$ with $27.5 \mathrm{hr}$ at maximum temperature, resulted in 39 percent of the span length rafted as compared to a blade exposed to cycles $B$ and $D$ with $55.5 \mathrm{hr}$ at maximum temperature, rafting over 44 percent of the span length. Exposing a NASAIR 100 blade to all of the engine cycles, $78.5 \mathrm{hr}$ at maximum temperature, resulted in 60 percent of the span length rafted. The leading and trailing edges of the blades rafted over essentially the same amount of the span.

The rafting behavior at the surface of the blades exposed to all cycles deviated from the rafting observed in the interior of the blade. At the surface the directional coarsening of the $r^{\prime}$ occurs parallel to the centrifugal stress axis (fig. $7(a)$ ). This anomalous rafting occurs on both pressure and suction sides of the blade and in both NASAIR 100 and Alloy 3 . The depth of the anomalous rafting varied along the length of the span with regions extending over $100 \mu \mathrm{m}$ beneath the surface. The anomalous rafting was observed to occur outside the span length of normal rafting. Electron microprobe analysis traversing normal to anomalous rafting showed no variation in chemistry. Blades subjected to cycles $B$ and $D$ and $C$ and $D$ did not exhibit the anomalous rafting (fig. $7(b)$ ).

\section{DISCUSSION}

The rafting behavior of the cross sections defined as leading and trailing edges were virtually identical. The amount of the blade span which rafted and the section of the blade which rafted were similar as was the maximum and minimum $r$ thickness measurements, parallel to the stress axis. The stress and temperature profile across the chord of the blade must be constant to induce such uniform rafting behavior. 
The presence of stress induced directional rafting has been observed to occur during an actual turbine engine operation. The aspect ratio versus the percent of span (fig. 5), yields a smooth curve on which the section of the blade that rafted can be easily depicted. The aspect ratio curves for $r$ and $r^{\prime}$ were identical. The aspect ratios measured here are in good agreement with those from laboratory creep tests (ref. 6).

The amount of the blade span rafted was determined to be a function of time at maximum temperature. Increasing the time at maximum temperature enabled sections of the blade at lower stresses and/or temperatures to form rafts. After $27.5 \mathrm{hr}$ at maximum temperature, a NASAIR 100 blade formed rafts only between a stress/temperature combination of $19400 \mathrm{ps} 1 / 1750{ }^{\circ} \mathrm{F}$ near the hub to $15000 \mathrm{ps} 1 / 1750^{\circ} \mathrm{F}$ near the tip of the blade. However, after $78.8 \mathrm{hr}$ at maximum temperature, a NASAIR 100 blade rafted due to a stress/temperature combination of $20200 \mathrm{ps} 1 / 1720^{\circ} \mathrm{F}$ near the hub to $13000 \mathrm{ps} 1 / 1735^{\circ} \mathrm{F}$ near the tip of the blade (fig. 5). Figure 6 shows the tendency to raft closer to the hub of the blade due to higher stresses over a virtualiy isothermal temperature profile. The coarsening kinetics are significantly lower at the lower stress and/or temperature sections of the blade. Only a 5 percent increase in the span length rafted occurred when the time at maximum temperature was increased. from 27.5 to $55.5 \mathrm{hr}$.

At least a 3 percent error in the measurement of the position of the span length rafted (fig. 6), could be expected. One source for error was the irregular shape of the blade cross section, which made it difficult to stay in the center of the cross section while transversing the span. Secondly, photographs were taken at only $1 \mathrm{~mm}$ intervals. This error could be responsible for the observed shift of the span rafted towards the hub for the blade exposed to stress rupture and mission mix (cycles $B$ and $D$ ).

Although the amount of the span rafted was a function of time at maximum temperature, the composition of the blade had a larger impact on the amount rafted. Consistent with the observations of Nathal (refs. 1 and 2), the $r^{\prime}$ coarsening rate was much lower for Alloy 3 than NASAIR 100 due to the lower magnitude of lattice mismatch for Alloy 3 . The range of the span rafted was smaller in Alloy 3 , with $78.8 \mathrm{hr}$ at maximum temperature, than for NASAIR 100 with only $21 \mathrm{hr}$ at maximum temperature.

In agreement with Mackay (ref. 6), the thickness of the $\gamma^{\prime}$ rafts were essentialiy the same thickness as the original $\gamma^{\prime}$ particles. However, the thickness of the rafted $\gamma$ was approximately three times its original thickness. This can be seen to arise from the fact that the $\gamma$ phase on two sides of the $\gamma^{\prime}$ particle must diffuse to form the rafted plates of $r$ thereby gaining a threefold increase in thickness.

The anomalous surface rafting was only observed in blades subjected to all four engine cycles ( $A$ to $D$ ). Blades subjected to cycles $B$ and $D$ and cycles $C$ and $D$ exhibited normal rafting to the surface with no evidence of anomalous rafting. The thickness of the anomalous rafts compare closely to the thickness of the original $\gamma^{\prime}$ particles, providing evidence of anomalous raft formation from the original $\gamma^{\prime}$. Therefore, the anomalous rafting had to occur during high cycle fatigue, cycle $A$, before normal rafting could occur in cycles $B$ and $C$. Work performed by Nathal and Mackay (ref. 7 ) has shown that anomalous rafting occurs in the threaded grip sections of isothermal stress- 
rupture samples where nonuniaxial stresses exist. The cause of the anomalous rafting is therefore believed to be due to an unknown complex stress at the surface of the blade during the high cycle fatigue engine test cycle.

SUMMARY

Stress induced directional rafting of single-crystal-nickel-base superalloy blades has been observed to occur during turbine engine operation. The amount of the blade span rafted was a function of temperature/stress profile, time at maximum temperature, and alloy composition. In general, for the specific temperature/stress profile of these blades, higher temperatures and stresses accelerated the rate of rafting. Increasing the time at maximum temperature enabled rafting at lower stresses and/or temperatures to occur. Rafts were observed where the stress/temperature combination was between $20200 \mathrm{psi} /$ $1720^{\circ} \mathrm{F}$ and $13000 \mathrm{ps} 1 / 1735^{\circ} \mathrm{F}$. Alloy composition had the largest influence, with NASAIR 100 rafting a larger percentage of the span than Alloy 3 under identical testing conditions. Anomalous rafting at the surface of the blade was observed for blades subjected to the high cycle fatigue test.

\section{REFERENCES}

1. M.V. Natha1 and L.J. Ebert: Meta11. Trans. A, 1985, vol. 16, pp. 1849-1862.

2. M.V. Natha1, R.A. MacKay, and R.G. Garlick: Mater. Sci. Eng., 1985, vol. 75, pp. 195-205.

3. T.E. Strangman, R.E. Dennis, and B.R. Heath: NASA CR-174652, National Aeronautics and Space Administration, Washington, D. C., 1984.

4. T.E. Strangman, G.S. Hoppin III, C.M. Phipps, K. Harris, and R.E. Schwer: in Superalloys 1980, J.K. Tien, ed., ASM, Metals Park, OH, 1980, pp. 215-224.

5. T.E. Strangman, B. Heath, and M. Fujif: NASA CR-168218, National Aeronautics and Space Administration, Washington, D. C., 1983.

6. R.A. Mackay and L.J. Ebert: Metal1. Trans. A, 1985, vo1. 16, pp. 1969-1982.

7. M.V. Nathal and R.A. Mackay: Unpublished Research, NASA Lewis Research Center, Cleveland, $\mathrm{OH}, 1986$.

TABLE I. - NOMINAL CHEMICAL COMPOSITION OF ALLOYS

[Weight percent.]

\begin{tabular}{|l|l|r|c|c|c|c|c|c|c|}
\hline Element & Mo & W & Ta & Ti & Cr & Co & Al & Hf & N1 \\
\hline ALLOY 3 & 0.8 & 9.5 & 3.3 & 1.1 & 8.5 & 5.0 & 5.7 & 0.3 & Balance \\
NASAIR 100 & 1.0 & 10.5 & 3.3 & 1.3 & 9.0 & 0 & 5.7 & 0 & Ba lance \\
\hline
\end{tabular}




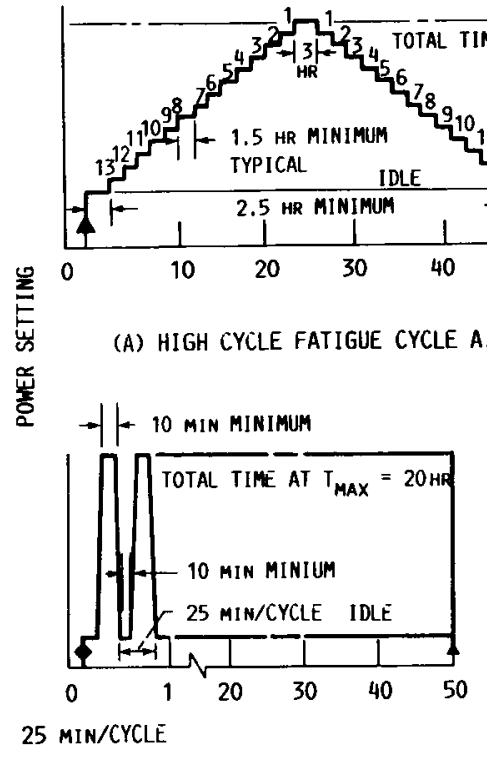

(C) LOW CYCLE fatigue CYCLE C.

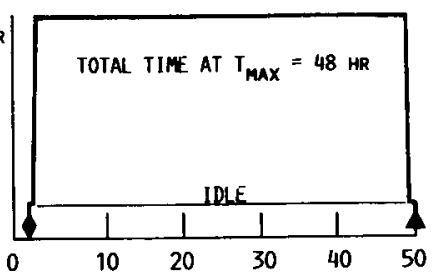

(B) STRESS RUPTURE CYCLE B. TOTAL TIME AT $\mathrm{T}_{\text {MAX }}=5.8 \mathrm{HR}$

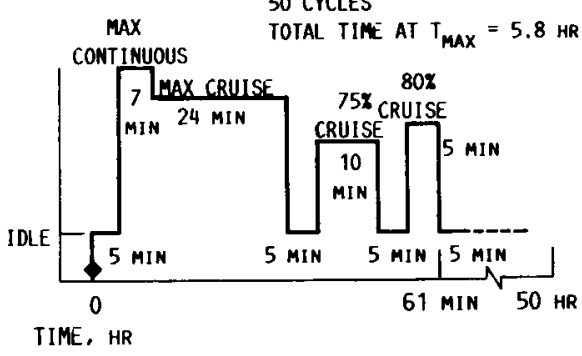

(D) MISSION MIX CYCLE D.

FIGURE 1. - ENGINE CYCLES.

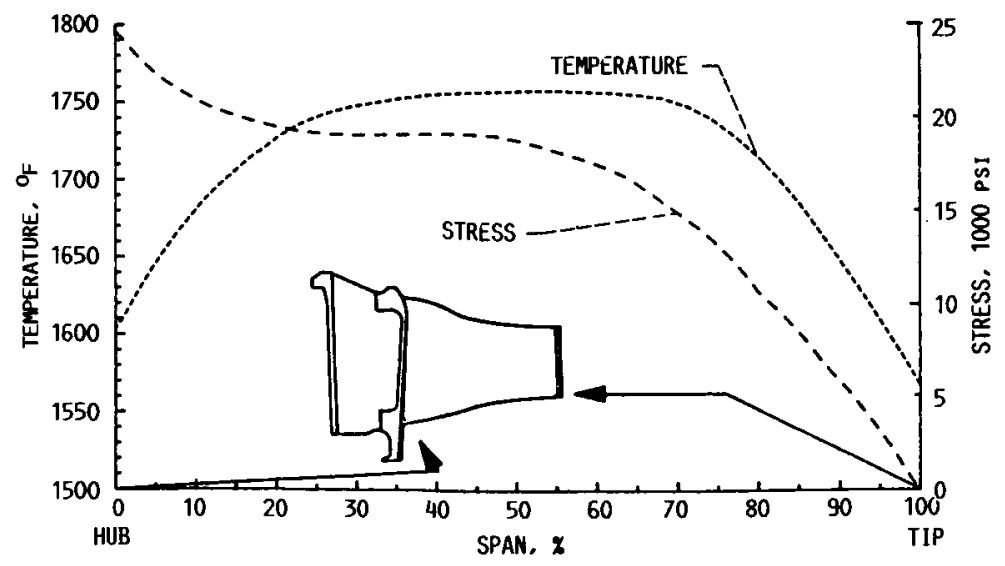

FIGURE 2. - AVERAGE STRESS AND TEMPERATURE PROFILE AT 100 PERCENT POWER. TFE 731 EXPERIMENTAL SINGLE CRYSTAL BLADE. 


\section{ORIGWAL PAGE IS \\ OF POOR QUALITY}

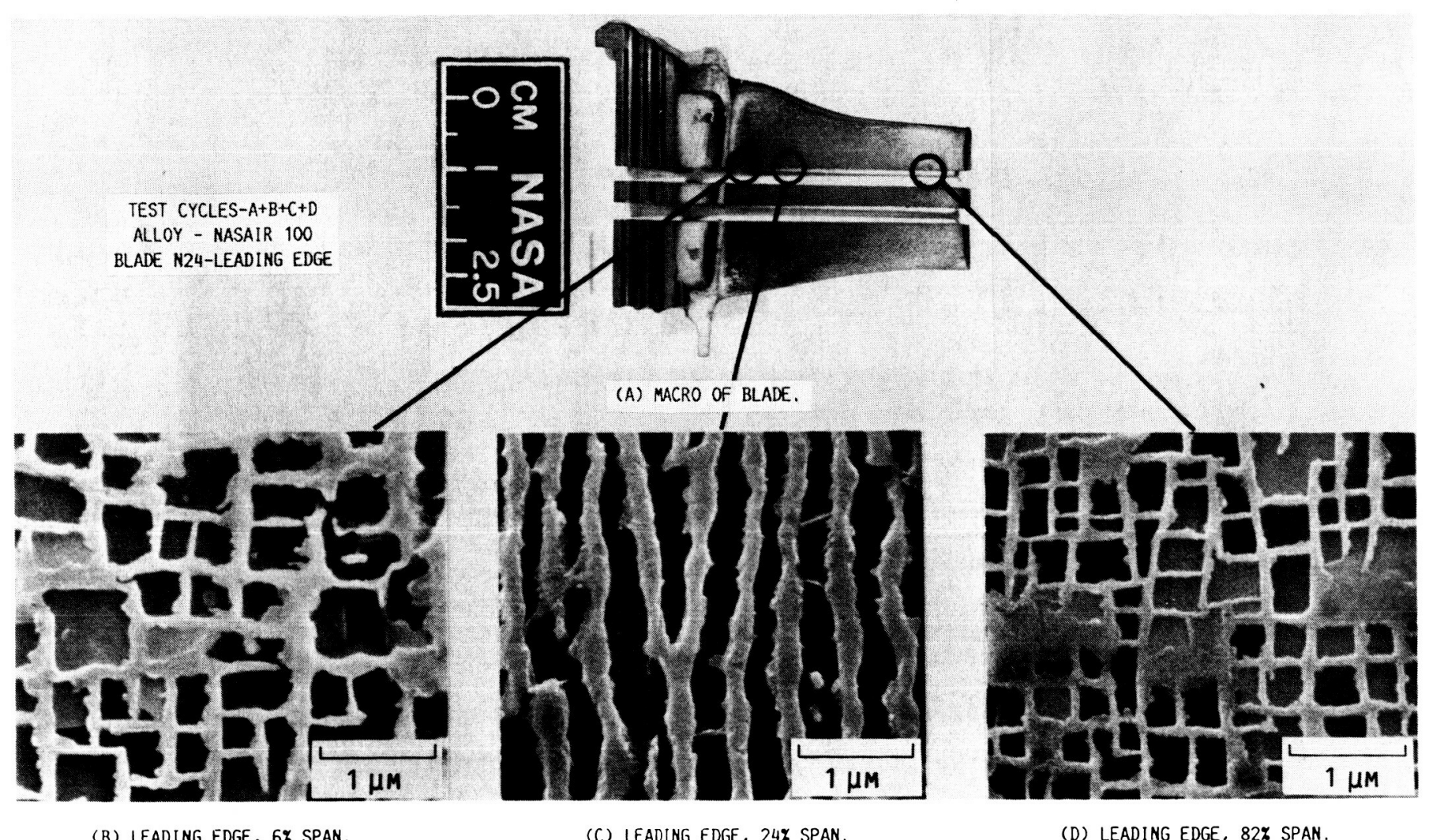

(B) LEADING EDGE, 6\% SPAN.

(C) LEADING EDGE, 24\% SPAN.

(D) LEADING EDGE, 82\% SPAN.

figure 3. - CHANGE OF MicrostruCtURE WITH SPAN FOR NASAIR. 100 BLADE EXPOSED TO ALL ENGINE CYCLES.

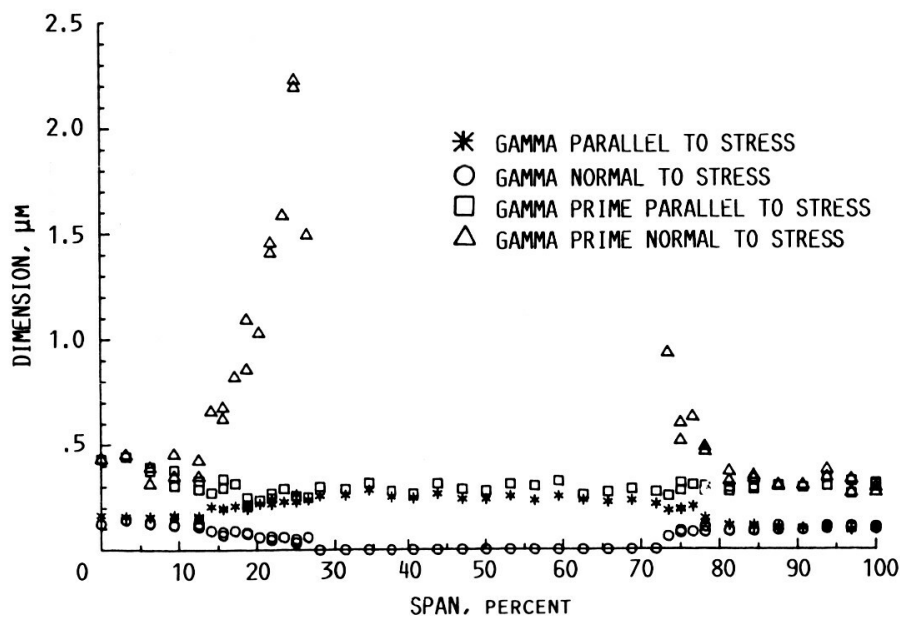

FiguRE 4. - CHANGE IN GAMMA AND GAMMA PRIME THICKNESS WITH SPAN. ALL TEST CYCLES, NASAIR 100, LEADING EDGE. 


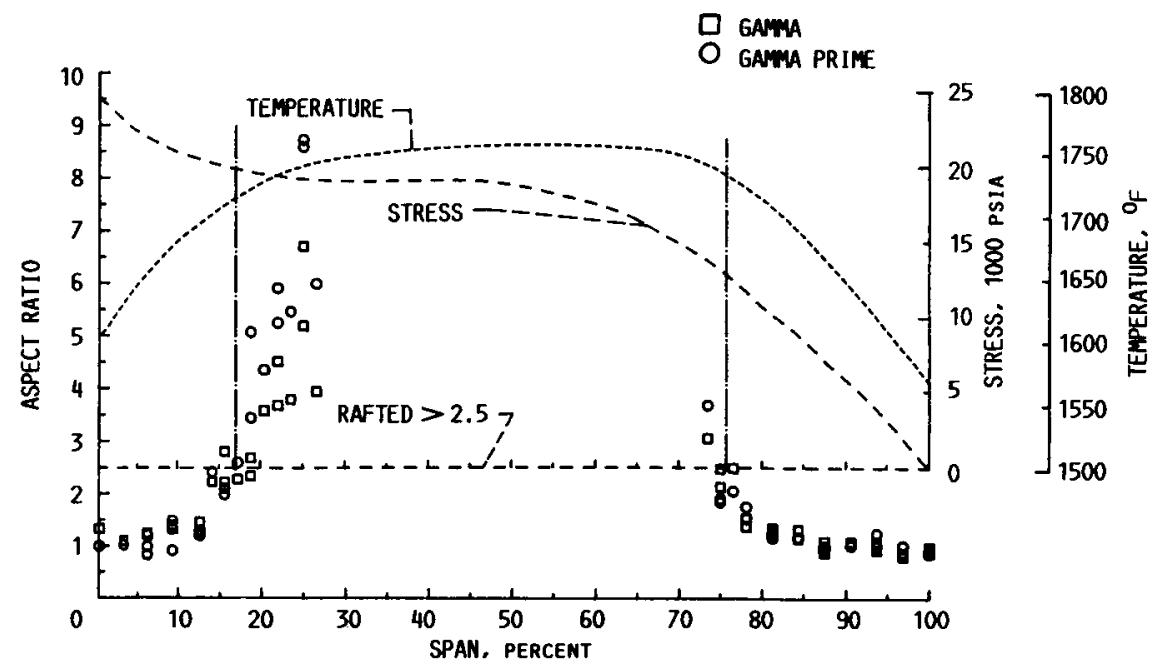

FIGURE 5. - CHANGE IN ASPECT RATIO WITH SPAN WITH AVERAGE STRESS AND TEMPERATURE PROFILE OVERLAID. ALL TEST CYCLES, MASAIR 100. LEADING EDGE.

RANGE OF SPAN RAFTED
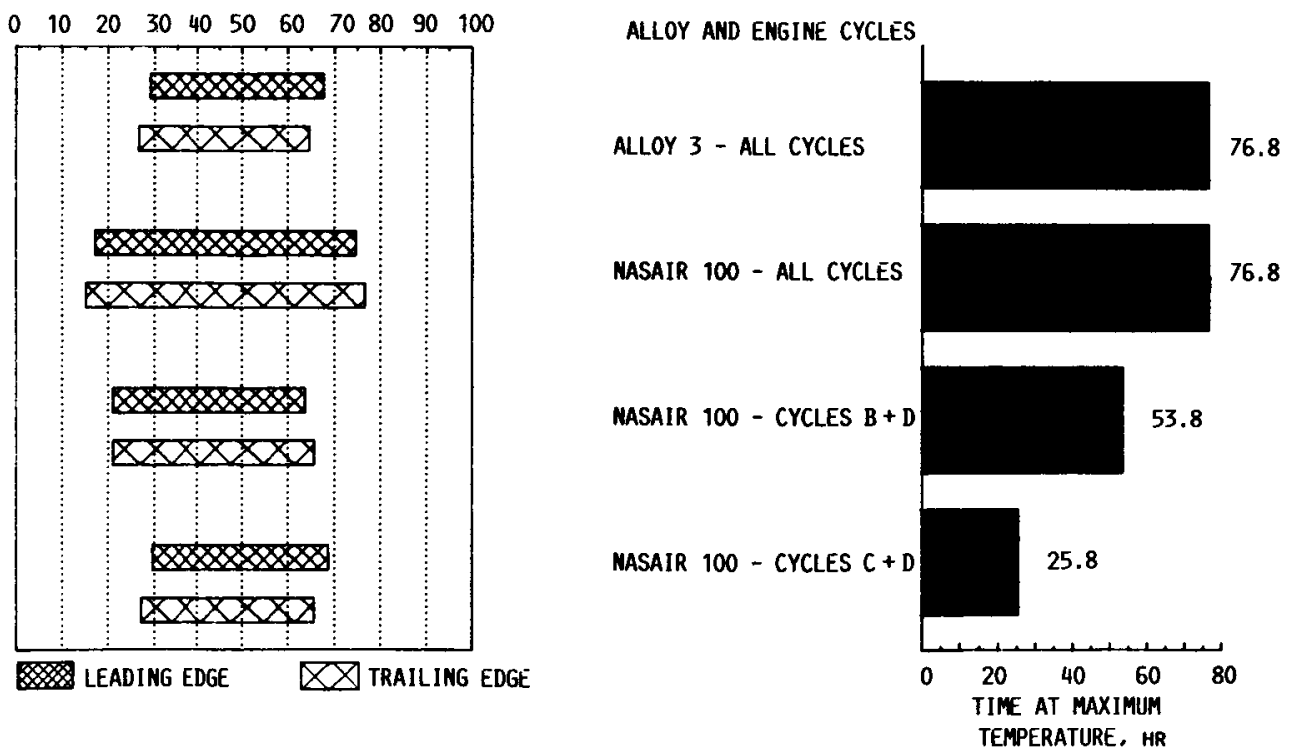

FIGURE 6. - SPAN LENGTH RAFTED AS A FUNCTION OF ALLOY AND ENGINE CYCLE. 


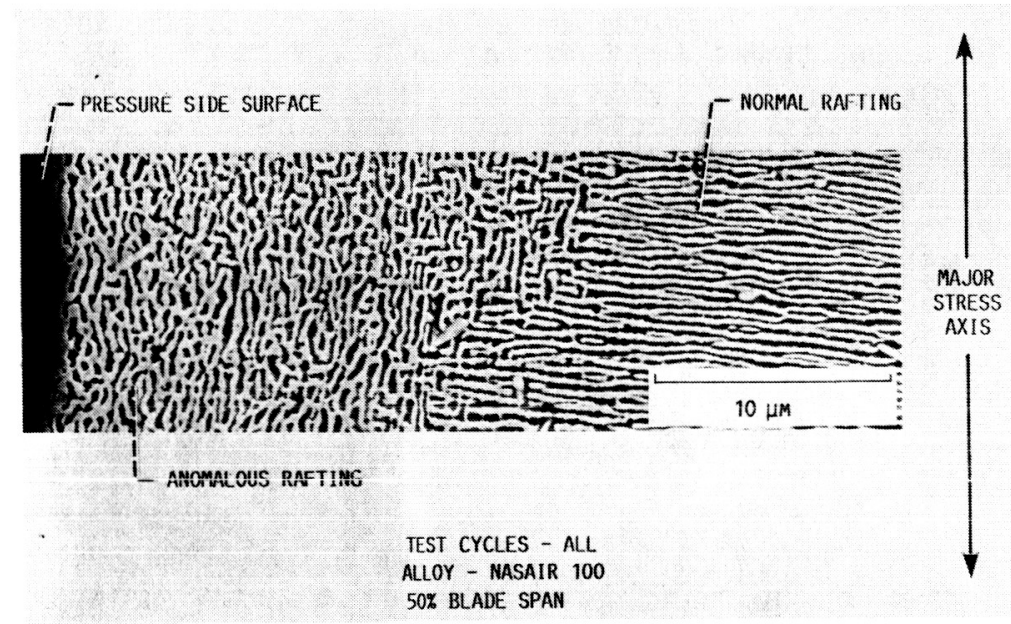

(A) ANOMALOUS RAFTING.

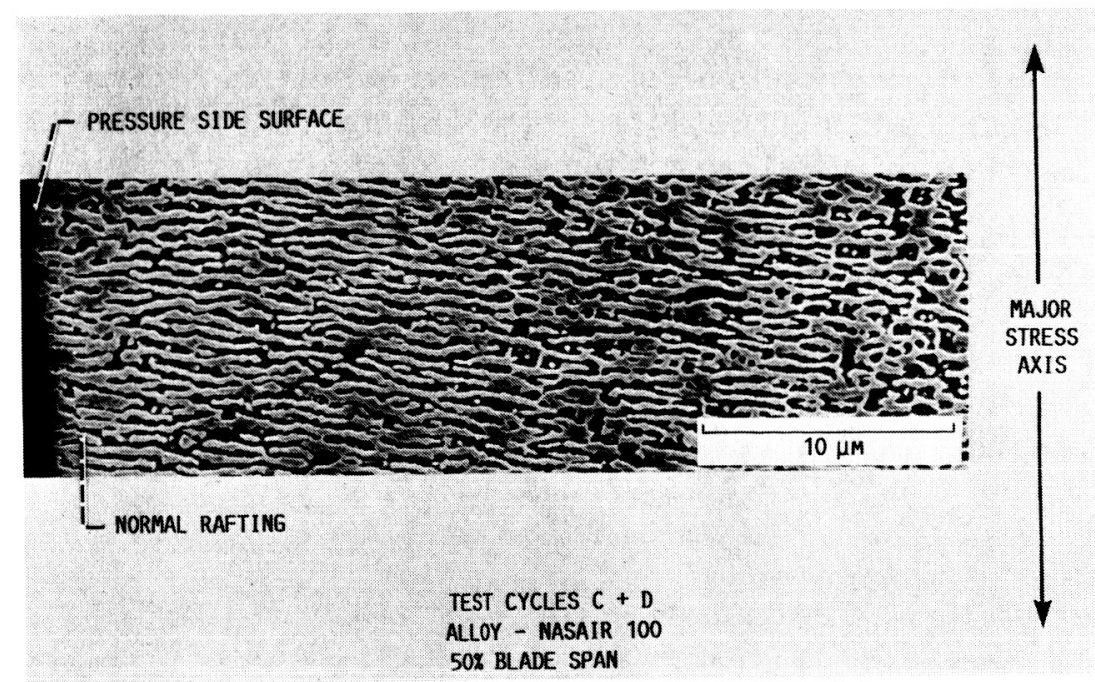

(B) NORMAL RAFTING.

FiguRe 7. - anOMALOUS AND NORMAL RAFTING at tURBine blade SURFACE. 


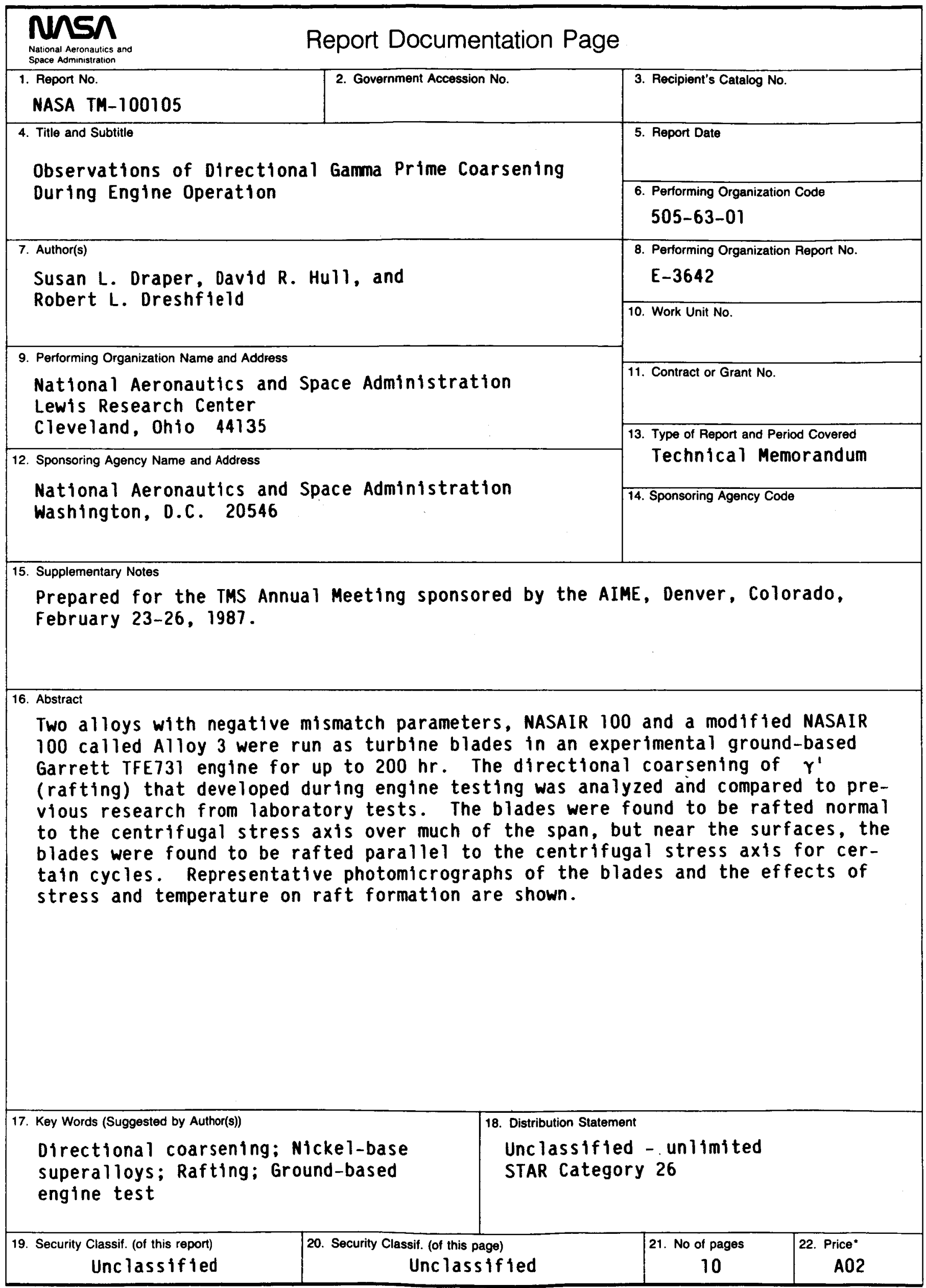

